\title{
ECMO in COVID-19-The Diffidence has to be Overcome by the Intensivists and Administrators in 2021
}

\author{
Poonam Malhotra Kapoor ${ }^{1}$ \\ ${ }^{1}$ Department of Cardiac Anaesthesia, CTC, AlIMS, New Delhi, \\ India527981
}

J Card Crit Care 2021;5:79-81.

In this phase of a shifting geopolitical order with the risk of China and increasing economic inequalities across the globe, there is confusion in understanding the economic recession. The pandemic has revealed one of the weakest links in the health system, that is, the institutional neglect of public district hospitals. We are now hopefully seeing a declining trend in the second wave of the pandemic in India. This is the most appropriate time to identify and plug the existing gaps on our health systems. We must act now to shore up our resources in all technologies to combat the COVID-19 virus with all forms of precaution at the local level and expertise of advanced technologies like mechanic ventilatory support to the failing lungs and heart in the form of extracorporeal membrane oxygenation (ECMO). The latter can be the foundation for a functioning and effective health in the intensive care unit (ICU) system. Guidelines and expertise from across the borders globally is the need of the hour. After the COVID pandemic dies down, it is the district hospitals and their infrastructure which should be strengthened by way of upgrading public health systems.

\section{ECMO in COVID-19 Pandemic}

What this pandemic, in both the first and the second phase, has indeed taught us is this: "Elevated D-dimer and fibrinogen levels are risk factors for ARDS and death patients with COVID-19." Thrombosis in COVID-19 patients caused due to severe acute respiratory syndrome (SARS)-COV-2, which is an excessive inflammatory state with raised interleukin (IL)-6 and lymphopenia showing poor prognostication of the disease progression ( - Fig. 1$)^{2}{ }^{2}$

What is essential to keep in mind is the type of patient cohort and the right selection for using timely ECMO as a bridge to lung transplant. The acute respiratory distress syndrome (ARDS) patients requiring lung transplant are extremely sick,

\author{
Address for correspondence Poonam Malhotra Kapoor, MD, \\ DNB, MNAMS, FIACTA(Hony), FTEE (Hony), FISCU (Hony), \\ Department of Cardiac Anaesthesia, CTC, AlIMS, New Delhi, 110029, \\ India (e-mail: drpoonamaiims@gmail.com).
}

thus requiring immense support, with or without ECMO, and without which their result would be fatal. One should strictly adhere to choosing the right patient and right time of starting $\mathrm{ECMO}^{3}$ in these ailing COVID patients. Thus, knowing the right indications and contraindications matter in initiating ECMO.

\section{Early ECMO Initiation is the Key to Success}

If unable to maintain ventilation and oxygenation with ventilator, then ECMO should be considered urgently. Delay in initiating ECMO, due to resource constraints or inability to procure the equipment, will prevent positive ECMO results from surfacing. Non-ECMO centers with deteriorating patients should refer patients to experienced ECMO centers. Today, in the pandemic, one case report mentions a successful ECMO as a bridge to lung transplant across two continents! As the mortality rate for wait-list, critically ill ARDS patients awaiting an ideal lung donor, becomes long it becomes ${ }^{5}$ mandatory for all to have ECMO in their COVID ICUs and learn the therapy from experts. ${ }^{5}$

\section{Indications of ECMO in COVID-19}

Some recommendations, as they stand today in June 2021, have been provided by the expert group. Indications for ECMO, as per latest ELSO guidelines, should remain unchanged in a pandemic. Indications and contraindications for ECMO must be followed as per the guidelines ( $\boldsymbol{- T a b l e s} \mathbf{1}$ and $\mathbf{2}$ ). As lymphopenia and respiratory failure are common presentations in COVID-19 patients, those that get admitted to the intensive care are extremely indisposed, with 7 to $13 \%$ requiring mechanical ventilation and/or noninvasive ventilation or ECMO for their ARDS. Which one of these patients would require a lung transplant is again dependent on several factors. Some indications for ECMO in COVID-19 as a bridge to transplant are well enumerated in $\mathbf{- T a b l e s ~} \mathbf{1}{ }^{4}$
DOI https://doi.org/ 10.1055/s-0041-1735345 ISSN 2457-0206 (c) 2021. Official Publication of The Simulation Society (TSS), accredited by International Society of Cardiovascular Ultrasound (ISCU).

This is an open access article published by Thieme under the terms of the Creative Commons Attribution-NonDerivative-NonCommercial-License, permitting copying and reproduction so long as the original work is given appropriate credit. Contents may not be used for commercial purposes, or adapted, remixed, transformed or built upon. (https://creativecommons.org/licenses/by-nc-nd/4.0/).

Thieme Medical and Scientific Publishers Pvt. Ltd. A-12, 2nd Floor, Sector 2, Noida-201301 UP, India 
After following the standard algorithm for the treatment of ARDS in COVID-19, attention should be focused to the following recommendations are suggested for successful outcome ( - Table 3 ).

\section{Reasons for Hesitancy in Initiating Early ECMO}

\section{Precautions and Learning ECMO the Right Way}

The ECMO mode used so far in most patients is venovenous (VV) ECMO across most global centers. The use of cardiorespiratory venoarterial (VA) ECMO among COVID-19 patients

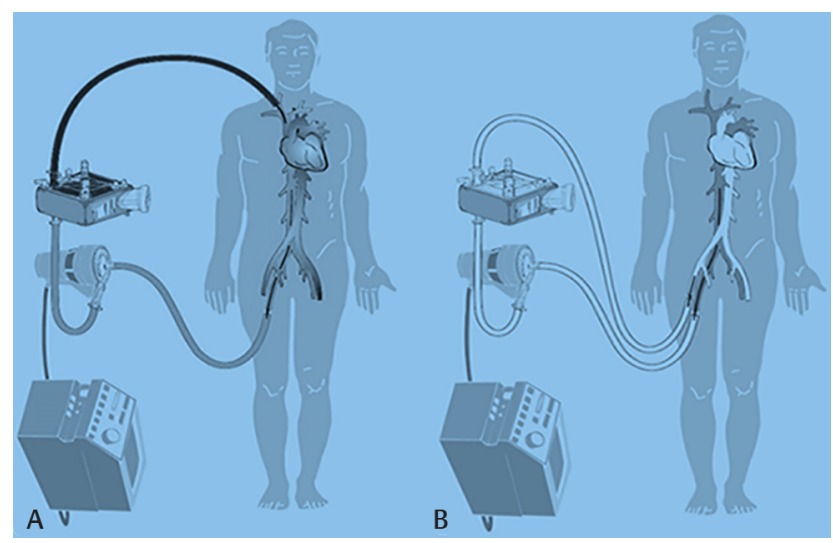

Fig. 1 Extracorporeal membrane oxygenation (ECMO) in the treatment of respiratory failure during COVID-19

Table 1 Indications of ECMO in COVID-19 ARDS

\begin{tabular}{|l|}
\hline Indications of ECMO \\
\hline Based on prepandemic guidelines from CESAR and EOLIA trials \\
\hline PF ratio of less than $50 \mathrm{~mm} \mathrm{Hg}$ for more than 3 hours \\
\hline PF ratio less than $80 \mathrm{~mm} \mathrm{Hg}$ for more than $6 \mathrm{~h}$ \\
\hline $\begin{array}{l}\text { Arterial blood pH less than } 7.25 \text { with PaCO2 of } 60 \mathrm{~mm} \mathrm{Hg} \text { or } \\
\text { more for } 6 \text { hour or more }\end{array}$ \\
\hline Immediate cardiac or respiratory collapse \\
\hline Barotrauma
\end{tabular}

Abbreviations: ARDS, acute respiratory distress syndrome; ECMO, extracorporeal membrane oxygenation.

Table 2 Depicting the contraindications of ECMO

\begin{tabular}{|l|l|}
\hline $\begin{array}{l}\text { Absolute contraindications of } \\
\text { ECMO }\end{array}$ & $\begin{array}{l}\text { Relative } \\
\text { contraindications of } \\
\text { ECMO }\end{array}$ \\
\hline Advanced age & Age $>65$ years \\
\hline Clinical frailty score $\geq 3$ & Consent not given \\
\hline $\begin{array}{l}\text { Significant underlying } \\
\text { comorbidities }\end{array}$ & Immunosuppressed status \\
\hline Multi system organ failure & Sepsis and bacteremia \\
\hline Acute cerebrovascular accident & Obesity (BMI $\geq 40$ ) \\
\hline Coagulopathy & $\begin{array}{l}\text { Contraindications to sys- } \\
\text { temic anticoagulation }\end{array}$ \\
\hline Inability to accept blood products & \\
\hline
\end{tabular}

Abbreviations: BMI, body mass index; ECMO, extracorporeal membrane oxygenation.
Table 3 Recommendations are suggested for successful outcomes

\begin{tabular}{|l|}
\hline Prone positioning and lung protective ventilation \\
\hline $\begin{array}{l}\text { Low-pressure, low-volume ventilation in all COVID-19 ARDS } \\
\text { patients unless contraindicated }\end{array}$ \\
\hline Care of comorbidities \\
\hline $\begin{array}{l}\text { Indications for ECMO, as per latest ELSO guideline should remain } \\
\text { unchanged in a pandemic }\end{array}$ \\
\hline Early ECMO initiation is the key to success \\
\hline Precautions and learning ECMO the right way \\
\hline $\begin{array}{l}\text { Administrative diffidence and resources shortage needs to be } \\
\text { overcome }\end{array}$ \\
\hline $\begin{array}{l}\text { Sweep off trials on VV ECMO in COVID-19 to breathe, start early } \\
\text { spontaneous ventilation }\end{array}$ \\
\hline $\begin{array}{l}\text { Suitable personnel, equipment, and resource are essen- } \\
\text { tial in Indian health and structure today }\end{array}$ \\
\hline $\begin{array}{l}\text { Suitable personnel, equipment and resource is essential } \\
\text { in Indian health and structure today }\end{array}$ \\
\hline
\end{tabular}

Abbreviations: ARDS, acute respiratory distress syndrome; ELSO, Extracorporeal Life Support Organization; VV ECMO, venovenous extracorporeal membrane oxygenation.

has so far been only approximately $10 \%$, and these patients too have been found to have a poor prognosis. Bleeding and thrombosis remain the most common complications when COVID-19 patients are put on ECMO. So what is the reason for this lack of positive results in ECMO during COVID-19? ${ }^{6}$

\section{Lack of Administrative Diffidence and Resource Shortage Needs to be Overcome}

The first is administrative regulations. There should be centralization and regulation of ECMO indications to overcome the shortage of ECMO resources. Both compassionate and commercial use of ECMO for fiscal benefits should be deferred in this pandemic.

Second involves taking the cost and complications too seriously. So far, outcomes of ECMO in COVID-19 patients have been rather dismissive. Centralize and regulate ECMO indications and contraindications to prevent a shortage of resources and inculcate a multidisciplinary teamwork culture in organizations. Approve ethical use of ECMO only and do not insert due to family pressures; compassionate or commercial use is imperative today. When to discontinue ECMO, too, is imperative.

The next pertains to knowledge of risks and complications in relation to the ECMO procedure. The knowledge of indications and complications is as imperative as the procedure.

\section{Sweep Off Trials on VV ECMO in COVID-19 to Breathe, Start Early Spontaneous Ventilation}

Third, the right time to wean off ECMO successfully is immensely relevant knowledge of weaning. In the final stages of weaning off ECMO, when there is hypercarbia often when requirements of oxygen are minimal, it is imperative as intensivists to anchor our minds and be mindful of the process of sweep off trials. Several authors have suggested that to predict suitability for decannulation, extended sweep off trials for some patients on VV ECMO is essential. The one deterrent 
for ensuring sweep off trials with minimal ( $0.5 \mathrm{~L}$ sweep) is the occurrence of plasma leak. Plasma leak occurrence can be circumvented by the judicious use of a Quadrox oxygenator. ${ }^{7}$ Without circuit clotting or failure events, in the sweep off trials, no oxygen is delivered to the circuit, so patients remains on or less than $30 \% \mathrm{FIO}_{2}$ oxygen. Also, in this setting of a bridge to Hemolung, extra carbon dioxide removal is very much feasible. A bridge to Hemolung is possible, according to Ali Usman et al, to let the patient off ECMO ventilation and breathe spontaneously. ${ }^{8}$ Presence of acidosis pre-ECMO, advanced age, lower $\mathrm{PH}$, higher $\mathrm{PCO}_{2},{ }^{8,9}$ and nonavailability of adequate resources are risk factors amongst survivors and non-survivors of COVID-19 patients, as seen in recent literature review.

\section{Suitable Personnel, Equipment, and Resource are Essential in Indian Health and Structure Today}

Finally, one main consideration should remain the availabilities of sufficient resources, including personnel and equipment. Concerns are still raised whether ECMO is justifiable in times of a pandemic, or if saving few lives would decrease the quality of care in other patients. ${ }^{10}$ As stated by the Sustainable Supply Chain Management (SSCM) and World Health Organization (WHO), this is not the time to start with implementing ECMO in centers which do not yet have the experience and resources for ECMO. However, in case of personnel, equipment, facilities and systems, our results suggest that ECMO could be considered as a supportive therapy in case conventional therapies are insufficient.

\section{Emotional Intelligence in ARDS and COVID-19 Patients}

In the COVID-19 pandemic era, clinical in person assessment might be limited by isolation needs and would require researchers to rely heavily on available metrics, which can be administered remotely. For example, without hawk-like clinical monitoring, ECMO drainage insufficiency may occur and ECMO failure ensues, with obstruction to the ECMO drainage at the outlet port itself.

\section{This JCCC special issue has a theme of Key issues in Post Covid Cardiac Critical Care}

In this special issue of JCCC on post covid critical care concerns, we have juxtaposed burning topics and trends in cardiac critical care, like platelet function analysis and also the need for care of the tracheostomized patient. All of the above-mentioned topics have been brought together along with futuristic trends in one frame. They create essential reading in JCCC's editorial, original, and review articles. I remain indebted to our invited guest editors, Dr. Klaus Gorlinger and Dr. Yatin Mehta, for their elucidative thoughts on the subject of platelet function analysis and tracheotomy, respectively. Do read this exciting JCCC issue and send across your views and reviews.

\section{Conclusion}

Intensivists dealing with ECMO in COVID-19 should be like a spring ECMO heart soaked with sincere subjective experience of srotriya (one who is a master of the knowledge of the subject of ECMO) and brahmnishta (one who is well-experienced in the truth of the ECMO procedure and its complications). It is not enough to rejoice in the siddhis of the mind and knowledge of ECMO alone. It is imperative to go forward and appeal to the minds of the health fraternity and the administrators to not just play around with idea of choosing the ECMO equipment for one's center, but learn from the experts, going ahead with the procedure right now. The inertia should within us, should hesitancy and diffidence within us of weighing the pros and cons of starting ECMO should be circumvented.

In the COVID era of ECMO initiation for COVID-19 patients, intensivists, as teachers, must be rejoicing at the opportunity to engage in the nuances of doing ECMO in COVID-19 subjects and not being reticent about them.

\section{Conflict of Interest}

None declared.

\section{References}

1 Huang L, Cao B. Post-acute conditions of patients with COVID-19 not requiring hospital admission. Lancet Infect Dis 2021;S1473-3099(21):00225--5

2 Malhotra Kapoor P. Editorial: COVID-19 thrombosis: An unsolved mystery. J Card Crit Care 2020;4:1-4

3 Tsiouris A, Budev MM, Yun JJ. Extracorporeal membrane oxygenation as a bridge A lung transplantation in the United States. ASAIO J 2018;64:689-693

4 Extracorporeal Life Support Organization COVID-19 Interim Guidelines A consensus document from an international group of interdisciplinary ECMO providers. Available at: https://www.elso.org/Portals/0/Files/pdf/ELSO \%20covid\%20 guidelines\%20final.pdf. Accessed August 4, 2021

5 Strueber M, Hoeper MM, Fischer S, et al. Bridge to thoracic organ transplantation in patients with pulmonary arterial hypertension using a pumpless lung assist device. Am J Transplant 2009;9(4):853-857

6 Schmid C, Philipp A, Hilker M, et al. Bridge to lung transplantation through a pulmonary artery to left atrial oxygenator circuit. Ann Thorac Surg 2008;85(4):1202-1205

7 Lebreton G, Schmidt M, Ponnaiah $M$, et al; Paris ECMO-COVID-19 investigators. Extracorporeal membrane oxygenation network organisation and clinical outcomes during the COVID-19 pandemic in Greater Paris, France: a multicentre cohort study. Lancet Respir Med 2021;(e-pub ahead of print). doi: 10.1016/S2213-2600(21)00096-5

8 Ali Usman A, Gutsche J. Essential topics in the management of venovenous extracorporeal membrane oxygenation in COVID-19 acute respiratory distress syndrome. J Cardiothorac Vasc Anesth 2021;35(9):2552-2555

9 Karagiannidis C, Mostert C, Hentschker C, et al. Case characteristics, resource use, and outcomes of 10021 patients with COVID-19 admitted to 920 German hospitals: an observational study. Lancet Respir Med 2020;8(9):853-862

10 Abrams D, Lorusso R, Vincent J-L, Brodie D. ECMO during the COVID-19 pandemic: when is it unjustified? Crit Care 2020;24(1):507 